\title{
PARA UMA COMUNICAÇÃO MAIS EFETIVA ${ }^{1}$
}

\author{
Towards a more effective communication
}

\author{
Rudolf Johannes Delhaas
}

Mestre em Ciência Agrícola pela University of Zambia (UNZA), Lusaka, Zâmbia, e em Neurobiologia e Educação pela Universidade de Groningen, Holanda, professor de licenciatura para professores de biologia na Universidade de Groningen, Holanda, Penha, SC - Brasil, e-mail: r.j.delhaas@bigfoot.com

\begin{abstract}
Resumo
O presente artigo aborda as diversas formas por meio das quais os seres humanos aprendem a limitar os impulsos do mundo externo e como manipulam dentro de si mesmos os impulsos selecionados. A comunicação intrapessoal serve-se de uma língua, única para cada pessoa, capaz de caracterizá-la. Este artigo procura responder as seguintes questões: como se estabelecem as intenções, as expectativas e os desejos por trás da comunicação? O que se passa no interior de uma pessoa ao assimilar seletivamente os estímulos do mundo, do próprio corpo e da própria mente, manipulando-os para devolver algum comportamento por gestos ou palavras? Como interagem os componentes da mente processando o que entra e o que sai da pessoa?

Palavras-chave: Comunicação intrapessoal. Seleção de estímulos. Processamento dos impulsos e dos estímulos. Linguagem verbal. Linguagem não-verbal. PNL.
\end{abstract}

\section{Abstract}

This article details the many ways by which people learn to limitate impulses from outside world and how they manipulate the selected incoming stimuli within themselves. The inner dialogue uses a language that is unique for each person. This article aims to answer these

\footnotetext{
1 Este artigo é uma adaptação de uma parte do seu último livro Het Leren Uitgedaagd (A Aprendiragem Desafiada), 2004, UOCG, State University of Groningen, Holanda.
} 
following questions: how do the intentions, expectations and desires that lies behind communication establish themselves? What happens inside a person in the process of selective assimilation of the stimuli that comes from the world, the body and the mind, manipulating them to return some reaction by gestures or words? How do mind's components interact with each other in processing what comes in and what goes out of it?

Keywords: Inner dialogue. Selection of incoming stimuli. Processing of incoming stimuli and impulses. Verbal language. Non-verbal language. NLP.

\section{INTRODUÇÃO}

A prestação de serviços apresenta atualmente um crescimento constante. Milhares de jovens estão sendo solicitados a colocar em prática suas competências na colaboração com outras pessoas, sejam colegas, supervisores, subalternos, alunos ou clientes. Tanto a colaboração como a prestação de serviços só poderão ser bem executadas quando a comunicação for efetiva.

Toda comunicação tem dois contextos: um interpessoal, ou seja, entre as pessoas, chamado de diálogo externo, e outro intrapessoal, que ocorre dentro das próprias pessoas, chamado de diálogo interno. A maior parte dessa comunicação tem por objetivo movimentar, desenvolver ou alterar os próprios hábitos ou de outras pessoas, porém, caso se desconheça o que motiva a nós e às outras pessoas, o alcance dos objetivos dessa comunicação fica comprometido. Portanto, todos os tipos de profissionais precisam conhecer o contexto intrapessoal para aumentar a eficácia comunicacional.

O texto a seguir refere-se ao contexto intrapessoal da comunicação, uma vez que já existe uma quantidade significativa de textos sobre a comunicação interpessoal. As principais perguntas que se deve fazer são: a) Como se estabelecem as intenções, as expectativas e os desejos por trás da comunicação?

b) O que se passa dentro de uma pessoa ao assimilar seletivamente os estímulos do mundo, do próprio corpo e da própria mente, manipulando-os para devolver alguma reação por gestos ou palavras?

c) Como colaboram os componentes da mente processando o que entra e o que sai?

Esses aspectos são muito importantes para todos os profissionais que trabalham com outras pessoas e que almejam eficiência para "tocar o ponto certo" do cliente.

O empreendimento não é simples. Para compreender-se essas questões, há um esquema bastante complicado à primeira vista, entretanto, pretende-se aqui desvendá-lo gradualmente, explicando cada um dos termos.

\section{O diálogo interno é a base do diálogo externo}

Todo mundo se comunica 24 horas por dia, consigo e/ou com outras pessoas, sobre si mesmo, sobre outras pessoas e/ou sobre outras coisas (Figura 1). 


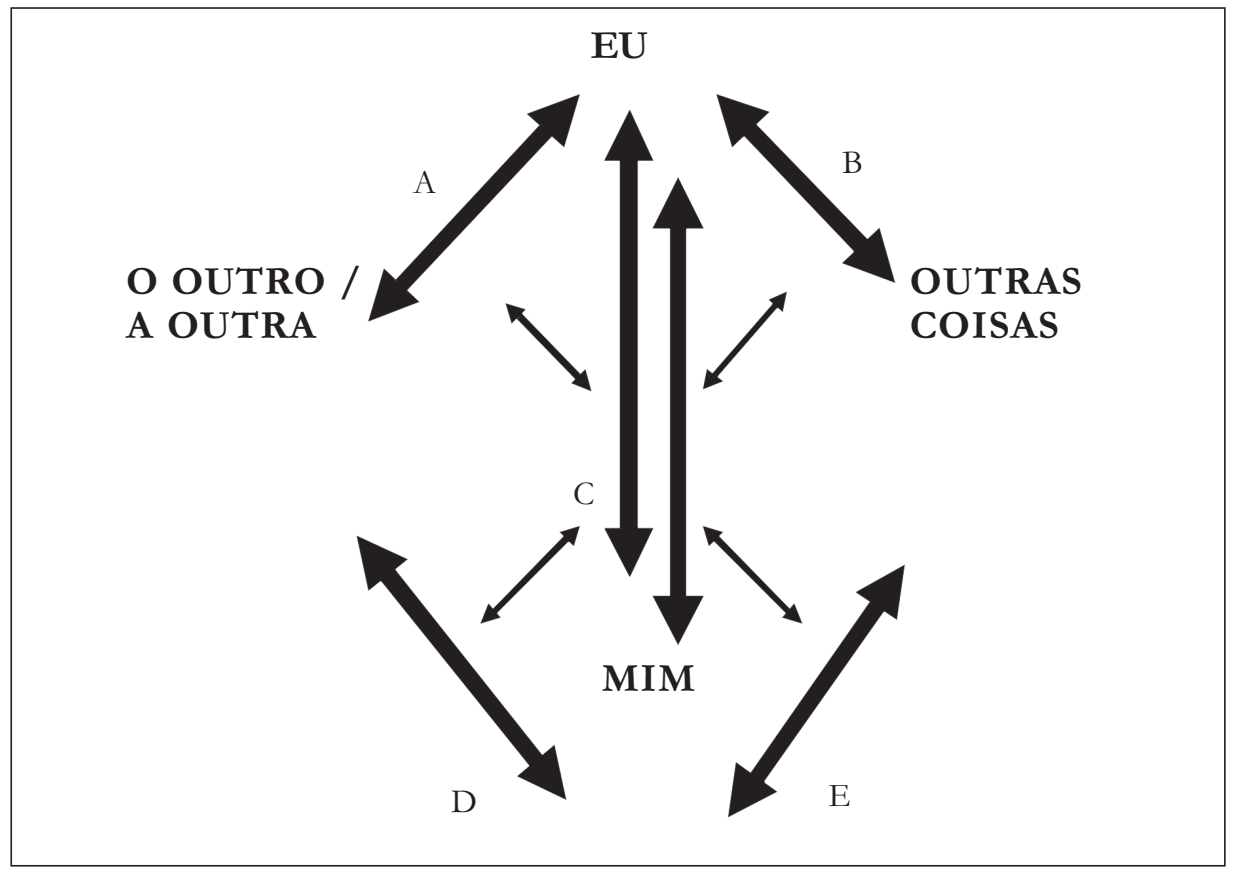

Figura 1 - O diálogo interno

A base da comunicação é a flecha dupla $\mathrm{C}$, que influencia cada outra relação comunicativa (quando se é um perfeccionista orgulhoso, não se pode ser imparcial em relação aos desempenhos das outras pessoas).

\section{Um casamento frutífero das ciências}

O linguista John Grinder (1975a), pesquisando modelos da aquisição da linguagem, encontrou o psicólogo Richard Bandler (1975b), que pesquisava modelos da aquisição das neuroses.

O palco desse encontro foi em Santa Cruz, Universidade de Califórnia, em meados dos anos 70. Brincando, decidiram aplicar os modelos da gramática transformacional de Noam Chomsky ao desenvolvimento humano. Atraíram, assim, a atenção e colaboração de muitos especialistas interessados nesse assunto.

\section{A contribuição do linguista John Grinder (1975)}

Fundamentalmente, na mente humana são armazenados todos os elementos necessários para aprender, compreender e falar uma língua (o idioma, as regras gramaticais e semânticas). Esse armazém é chamado de Estrutura do Fundo da Língua (EFL). A EFL se forma quando se fica muito tempo em um determinado ambiente. No início da vida, por meio da aprendizagem, por tentativa e erro, aprende-se a discriminar, entre os muitos sons, quais são da língua humana e quais são significantes nesse ambiente. Só o vértice dessa EFL é audível como língua falada, chamado de Estrutura de Superfície da Língua (ESL). Os linguistas pesquisam a ESL para compreender ou conhecer a EFL.

\section{Os filhos do matrimônio científico de Bandler e Grinder}

Bandler \& Grinder (1975) sugerem que, se é possível aprender algo da EFL pela observação da ESL, seria possível descobrir algo da Estrutura do Fundo da Mente (EFM) e das seleções que a pessoa utiliza para construir seu comportamento pessoal por meio da observação do comportamento pessoal, chamado por eles de Estrutura da Superficie da Mente (ESM).

Bandler and Grinder (1975) observaram criteriosamente alguns profissionais bem sucedidos e os entrevistaram. A partir disso, identificaram que existem 15 tipos de filtros, usados em cinco 
momentos do processo de assimilação seletiva dos estímulos do mundo, do próprio corpo e da mente, manipulando-os para devolver alguma reação por gesto ou palavra. Os tipos de filtros não são pessoais; têm um caráter universal e, portanto, são pouco determinados pela cultura.

Esses autores identificaram que cada pessoa usa os filtros de maneira pessoal, numa escala de intensidade variável. Comparando cada filtro a uma tecla corrediça na mesa de ajustes dos recursos de um palco de teatro (luz, som, cenário etc.), tem-se que para uma pessoa pode ser que esteja ligada a tecla da luz vermelha numa intensidade brilhante e, para outra, essa tecla esteja sempre numa intensidade pálida.

Eles descobriram também que cada indivíduo concede uma prioridade pessoal aos diferentes filtros. O senhor A pode ser muito sensível à luz/imagens, enquanto o senhor B pode ser mais afetado por sons/palavras e tons. Essa totalidade da organização pessoal dos filtros é percebida por si mesmo e pelos outros como o caráter ou a personalidade de uma pessoa.

\section{Necessidade de selecionar}

As pessoas recebem estímulos continuamente, tanto do ambiente como do corpo, alma e coração. $\mathrm{Na}$ Figura 2, chamaremos de realidade a todos os estímulos possíveis do ambiente e de dentro de nós - o "Tudo". Como são muitos, não é possível perceber todos ao mesmo tempo; assim, faz-se uma seleção desses estímulos, para a manutenção da saúde mental e corporal.

Inicialmente, utiliza-se para isso dois instrumentos de seleção: a Seleção $A$, relativa às preocupações temporárias; e Seleção E, referente aos hábitos pessoais, as ratificações recebidas dos ambientes em que se vive e as crenças pessoais.

A Seleção A abarca as preocupações temporárias e permanentes permitem que certos estímulos entrem na Estrutura de Fundo da Mente (EFM) mais facilmente do que outros. Quem acabou de quebrar sua perna está consciente dos muitos e fortes estímulos do seu corpo, mas se ela for exposta a outros estímulos (como assistir a uma novela ou a um filme que chame sua atenção), poderá mudar o foco de sua atenção. Uma pessoa que costuma ter medo em uma visita a um bazar árabe pode apresentar uma preocupação excessiva de se perder, o que pode ser a causa de apenas se assimilar a metade do que seria possível.

No caso da Seleção E, cada pessoa tem pressupostos, verdades pessoais às quais ela está habituada e que são parcialmente confirmadas pelas pessoas com quem ela convive. Esses valores e convicções filtram diretamente a informação disponível potencial-mente. Além disso, a Seleção E pode influenciar indiretamente as preocupações temporárias, transformandose em seleção A. Por exemplo, quando os vizinhos acabam de comprar um carro de modelo novo e esse tem importância para alguém como símbolo de prestígio, subitamente essa pessoa passa a observar o mesmo modelo de carro em diversas ruas da sua cidade. 


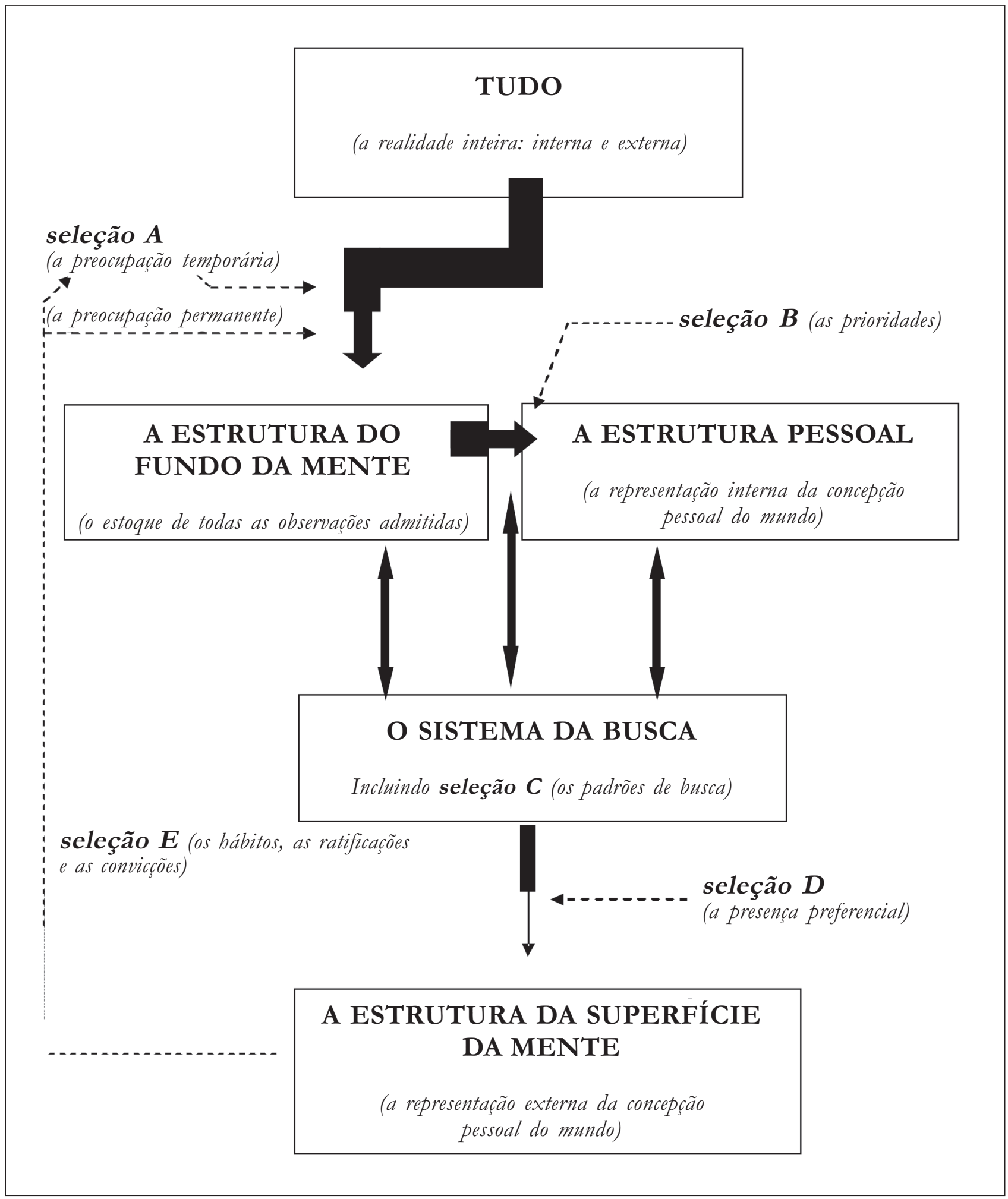

Figura 2 - Esquema do sistema intrapessoal para selecionar e armazenar impulsos e para representar-se no mundo 
Essas duas seleções - A e E - são apenas uma pequena parte de tudo o que poderia ser percebido e que entra na EFM. No esquema apresentado a flecha fica mais fina. Além disso, a EFM é ainda um armazém enorme de dados a respeito do mundo interno (corpo [o corpo é interno?], mente e coração) e do mundo externo (ambiente). Desse armazém as pessoas tiram os componentes para construir concepções pessoais do mundo.

Todos os dados que estão relacionados na EFM são chamados de Estrutura Pessoal (EP). É possível notar que no esquema a flecha fica, mais uma vez, mais fina. Os dados na EFM serão discutidos mais à frente, lembrando que quando os dados ficam muito tempo da EFM poderão ser apagados.

Seleção B: sendo confrontado com a realidade (interna e externa), que muda permanen-temente, todos ficam conscientes de suas concepções do mundo e da necessidade de ajustá-las às vezes. As prioridades do momentoajudama selecionaroqueévantajoso. Quando Pedro, o gerente, está com pressa para acabar um assunto, ele pode procurar economizar tempo, mas deixa de perceber os sinais do ambiente, que pode se desarmonizar.

\section{O sistema de busca}

Cada pessoa guarda e protege suas concepções pessoais do mundo, revelando-as apenas para outras pessoas e para si mesma quando elas são aceitáveis ou proveitosas. Para acessá-las, serve-se de duas seleções: C e D. Assim, nota-se que no esquema a flecha fica ainda mais fina.

A Seleção C refere-se ao que se busca de maneira apenas parcialmente intencional na EP (e, às vezes, também na EFM), por meio de padrões de busca que são totalmente pessoais, de acordo com limitações e preferências. Muitas pessoas buscam recordações, preferencialmente, folheando um álbum de fotografia: elas estão utilizando um padrão visual de busca. Outras recordam palavras, exclamações ou declarações: estão preferencialmente utilizando um padrão auditivo de busca. Existem pessoas que só precisam se concentrar em seu próprio corpo e coração (sentimentos) para evocar recordações. Elas estão utilizando o padrão cinestésico de busca. Todos conhecem esses fenômenos em sentido inverso: toda espécie de estímulos externos, sejam visuais, auditivos, cinestésicos, olfativos ou combinações desses, podem, repentina e involuntariamente, reavivar recordações.

Na Seleção D, nem sempre desejamos expressar toda nossa concepção do mundo. Usase, então, nosso "guarda-costas mental", um guardião da nossa presença preferencial. O guardião se preocupa com duas perguntas:

a) a pergunta do papel: como quero estar presente agora? Como expectador, líder, ajudante, cooperador, distante, aprendiz etc.?

b) a pergunta da imagem: como quero impressionar as outras pessoas? Como espertalhão, inocente, vítima, mandão, amigo etc.?

Toda essa expressão, seja voluntária ou involuntariamente, nas palavras, ações, gestos e postura corporal, é chamada de Estrutura de Superfície da Mente (ESM). As pessoas com as quais convivemos reagem a essas ESM positivamente, confirmando-nos ou negando alguns aspectos. As reações dos outros influenciam a seleção E: os hábitos, os valores e as crenças, incluindo aí as próprias "verdades".

\section{O diálogo interno e o diálogo externo falam duas línguas: A língua materna e a língua original}

Podemos dizer que o desenvolvimento humano, da concepção até a morte, é a maior maravilha do mundo. Consideremos apenas o desenvolvimento da fala e da aprendizagem da língua materna: uma língua com muitas e complexas regras gramaticais, duplos sentidos dependentes do contexto, provérbios, ditados e metáforas. Essa aprendizagem demora muitos anos e está em grande parte influenciada e controlada pelo ambiente social. Abrange também as aprendizagens não-verbais (o sotaque e os acentos, a melo-dia das frases, a mímica, os gestos etc.).

Além disso, cada um desenvolve uma “língua original". É a maneira pessoal de processar experiências interna e externamente: interpretá-las, colocá-las em ordem e guardá-las para usá-las futuramente. Em comparação com o desenvolvimento da língua materna, o crescimento da língua original não é tão escrupulosamente 
condicionado pelo ambiente social; a língua original também não obedece às regras gramaticais comuns e significações padronizadas. ${ }^{2}$

A língua original também inclui o aprendizado de muitos hábitos não-verbais pessoais. Enquanto a língua materna permite a comunicação entre indivíduos, a língua original determina a diferenciação dos indivíduos.

Não existe apenas uma língua original e nenhuma língua original iguala-se a outra língua original, porque cada pessoa é única. Evidentemente, há semelhanças entre as línguas originais, mas existem muitas diferenças decorrentes da índole e da personalidade de cada um (Tabela 1).

Tabela 1 - Alguns exemplos da língua original

\begin{tabular}{|c|c|c|c|}
\hline $\begin{array}{l}\text { Situações ou } \\
\text { comportamento }\end{array}$ & \multicolumn{3}{|c|}{ Sinais verbais e não verbais } \\
\hline Perigo repentino & $\begin{array}{l}\text { o corpo contrai-se, crispa-se } \\
\text { (olhos, braços e ombros fechados) }\end{array}$ & o corpo abre-se (olhos, braços & , pernas) \\
\hline Medo crescente & fala mais alto ou mais rápido & fala mais baixo ou mais devage & \\
\hline Raiva iminente & $\begin{array}{l}\text { aumentar-se ou envelhecer-se } \\
\text { (volume do voz, postura) }\end{array}$ & reduzir-se, rejuvenescer-se & \\
\hline $\begin{array}{l}\text { Pressão do ambiente } \\
\text { Verbo auxiliar preferi- } \\
\text { do }\end{array}$ & $\begin{array}{l}\text { apressar-se } \\
\text { dever, ter }\end{array}$ & $\begin{array}{l}\text { lentidão } \\
\text { querer }\end{array}$ & poder \\
\hline Primeira atenção & o que está aí & o que não está aí & \\
\hline Comparece-se com... & ...si mesmo & ...alguém outro & \\
\hline $\begin{array}{l}\text { Relaciona o que acon- } \\
\text { tece... }\end{array}$ & ...ao passado & ....ao presente & ....ao futuro \\
\hline $\begin{array}{l}\text { No caso das decisões } \\
\text { investe... }\end{array}$ & ...em seguir procedimentos & $\begin{array}{l}\text {...em deixar em aberto todas } \\
\text { as opções }\end{array}$ & $\begin{array}{l}\text {...em apegar-se } \\
\text { estruturas }\end{array}$ \\
\hline Age & evitando & Apanhando & \\
\hline Com problemas & pensa e pondera & sente & age \\
\hline
\end{tabular}

\section{Os filtros colaboradores do teclado}

Na mesa de recursos teatral, as teclas de som, luz e dos cenários são manipuladas separadamente pelos técnicos, seguindo as ordens do diretor de produção para proporcionar uma aventura multidimensional e multimídia.

Imagine que cada ser humano também tenha uma mesa de recursos com teclas reguláveis para cada filtro. Os filtros são:

a) os verbos auxiliares;

b) os hábitos linguísticos pessoais;

\footnotetext{
2 A palavra 'casamento' pode provocar uma multidão dos sentimentos e emoções: 'proteção', 'chance de crescimento pessoal', 'prisão', não-obrigatoriedade', 'incerteza', 'segurança', 'prestígio', 'dinheiro' etc.
} 
c) o salva-vidas (pensar, sentir, agir);

d) as modalidades e submodalidades (os sentidos: ouvir, olhar, cheirar, gostar, tocar);

e) a atitude básica: aspirar a algo ou evitar;

f) a atitude básica: procurar diferenças ou semelhanças;

g) a atitude básica: comparar;

h) a atitude básica: ponto de referência interno ou externo;

i) a atitude básica: experimentar a partir de dentro ou a partir de fora;

j) a perspectiva do tempo: hoje, ontem, amanhã;

k) a experiência do tempo;

l) os valores e convicções;

m) o nível de abstração e fragmentação;

n) o tipo da recordação primeira (lugar, pessoas, objetos, ações, informações);

o) o tipo da reação quando decisões precisam ser tomadas.

Bandler e Grinder (1975) descobriram que a organização de cada filtro causa ações perceptíveis específicas no comportamento, na língua e no corpo. Em grande parte, essas organizações de filtros preferenciais são aprendidas. Nos ambientes da nossa juventude, essas organizações aumentam as possibilidades de sobreviver ou alcançar objetivos. Infelizmente, muitas pessoas não percebem que, para se realizar, precisam de outras organizações quando se mudam para outros ambientes. No entanto, elas nunca aprendem como fazer isso, o que se aplica às situações de sucesso e também às de problemas e de crise.

Quando uma pessoa se dá conta de que suas preferências de comunicação intrapessoal são, em grande parte, aprendidas, uma pergunta se impõe: o que aconteceria se mudasse apenas uma tecla? E o que aconteceria se mudasse duas ou seis teclas? Pode ser que todo o palco mudasse ou todos os papéis no mundo se alterassem. Vale lembrar, no entanto, como será descrito a seguir, que todas as organizações dos filtros não são essencialmente boas ou más. Tudo depende do ambiente e daquilo a que se aspira.
Filtro 1 - A força dos verbos auxiliares e algumas construções gramaticais

Certamente, todos conhecem pessoas que:

a) sempre 'têm que fazer' muitas coisas ou as exigem dos outros (os 'estressados');

b) sempre 'vão fazer' muitas coisas (os (procrastinadores');

c) sempre 'podem fazer tudo' (os 'onipotentes');

d) sempre 'querem' muitas coisas (os 'descontentes insaciáveis');

e) sempre sofrem de 'se eu tivesse' ou de 'se você tivesse' (os ‘desculpadores' e os 'acusadores');

f) sempre 'desejariam' muitas coisas (os 'arrependidos');

g) muitas vezes 'queriam' coisas (as pessoas com 'ânsias inativas');

h) frequentemente 'poderão' fazer algumas coisas (os 'hesitantes');

i) às vezes 'teriam que fazer' algumas coisas (os 'culpados indolentes').

Existem muitas construções gramaticais em colaboração com os verbos ter, ir, dever, querer, haver e poder, que podem influenciar a vida das pessoas e o seu comportamento profundamente. Cria-se e adota-se preferências e hábitos gramaticais dos quais, às vezes, não se tem consciência.

A vida alinha-se ao longo das construções usadas mais frequentamente. A preferência pode ser dependente (às vezes inconsciente) do contexto da nossa vida (com os pais: quero nadar; com os amigos: poderia nadar; com o professor: não vou nadar etc.).

\section{Filtro 2 - Mais alguns hábitos da língua original}

São quatro tipos de hábitos da língua (falada) original que podem causar problemas:

a) exclusões: permitem "ver apenas o que queremos ver"; 
b) generalizações: uma só experiência é amplamente validada;

c) deformações: um aspecto da experiência é deformado, porque essa observação não se ajusta a uma imagem já formada;

d) pressupostos particulares.

A Tabela 2 apresenta esses hábitos de maneira mais detalhada:

Tabela 2 - Hábitos da língua (falada) original

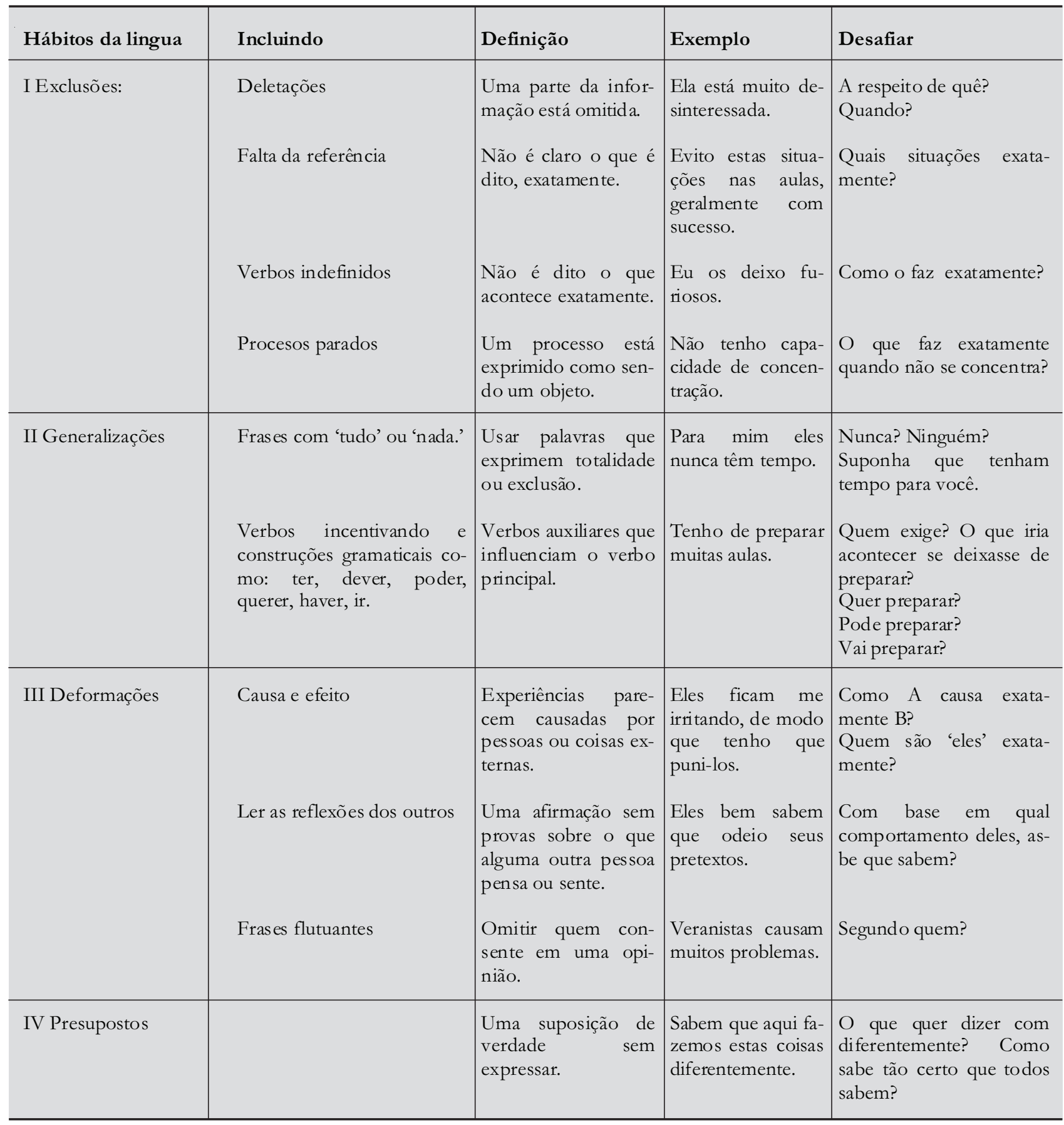




\section{Filtro 3 - O salva-vidas}

O salva-vidas adapta-se aqui como uma metáfora perfeita para explicar a colaboração entre a disponibilidade livre de: sentir $(\mathrm{S})$, pensar $(\mathrm{P})$ e agir (A) nas situações agradáveis e desagradáveis.

Quando nos sentimos muito bem, o salva-vidas apresenta-se como na Figura 3. O indivíduo está bem e tem equilíbrio, agilidade (mobilidade) e flexibilidade para responder a todas as ondas que vêm, mesmo que o tempo esteja ruim, porque está no centro do salvavidas, com os braços livres e relaxados.

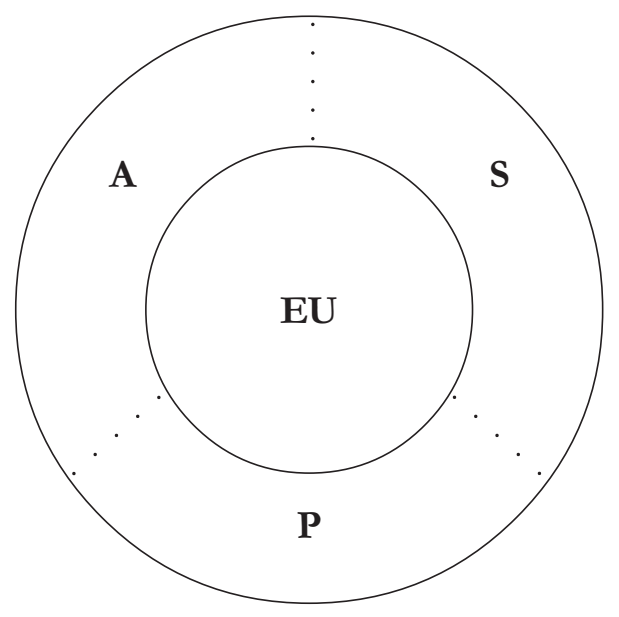

Figura 3 - As separações (divisórias) são semipermeáveis, de modo que existe sempre comunicação entre os três potenciais humanos: agir, sentir e pensar

Às vezes, as pessoas estão habituadas com uma das outras combinações: a pessoa pode estar no centro, mas na maior parte ao lado do salva-vidas e os braços ocupados, agarrando-se ao salva-vidas.

No caso apresentado na Figura 4, as divisórias entre pensar/sentir e entre agir/sentir ficam impermeáveis ou menos permeáveis. $\mathrm{O}$ comportamento é dirigido só para o raciocínio e a facilidade de sentir é isolada, fora do jogo. A pessoa lamenta muitas vezes: "pensando bem, teria que dizer X..." ou "no fundo teria de dizer não...".

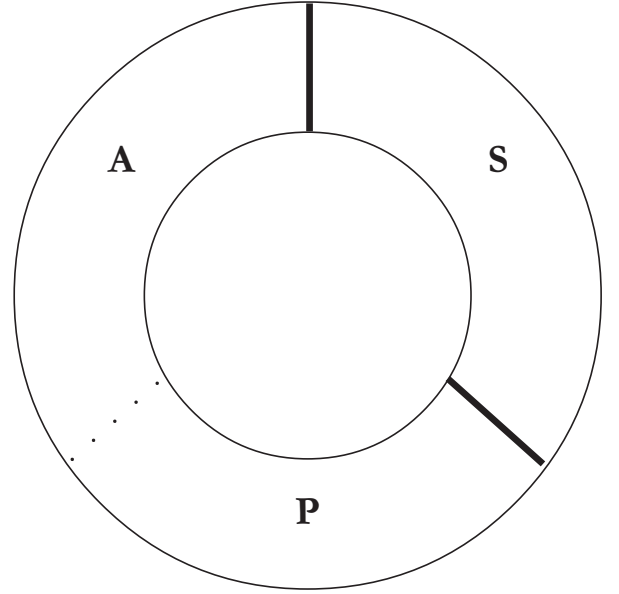

Figura 4 - Comportamento voltado para o agir/pensar

$\mathrm{Na}$ Figura 5, entre pensar e sentir a troca livre está bloqueada. $\mathrm{O}$ agir está dirigido, por sua vez, para sentir ou para pensar, sem confluência e congruência. A pessoa sente-se mais e mais fraca, não escolhendo entre agir sentindo ou agir pensando. O ambiente conhece-o como vacilante ou inconstante, às vezes, agindo racionalmente, às vezes agindo sentimentalmente e muito inconstante.

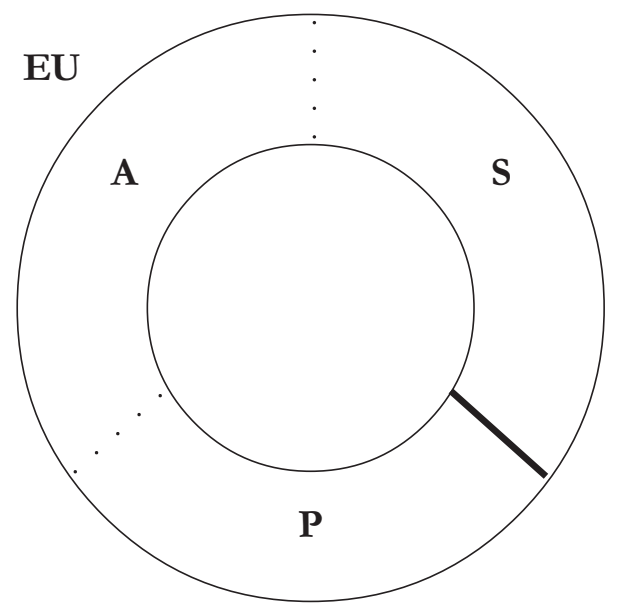

Figura 5 - Troca bloqueada entre pensar e sentir

No exemplo da Figura 6, entre pensar e agir a troca livre está bloqueada. $\mathrm{O}$ agir é dirigido para o sentir: as justificativas não são razoáveis. Para outras pessoas, é imprevisível ou incompreensível; a pessoa sente-se incompreendida, nenhum entendimento sobre como as coisas aconteceram ("porque eu senti assim"). A reflexão lógica pode ser muito valorizada, mas nunca compensa. 


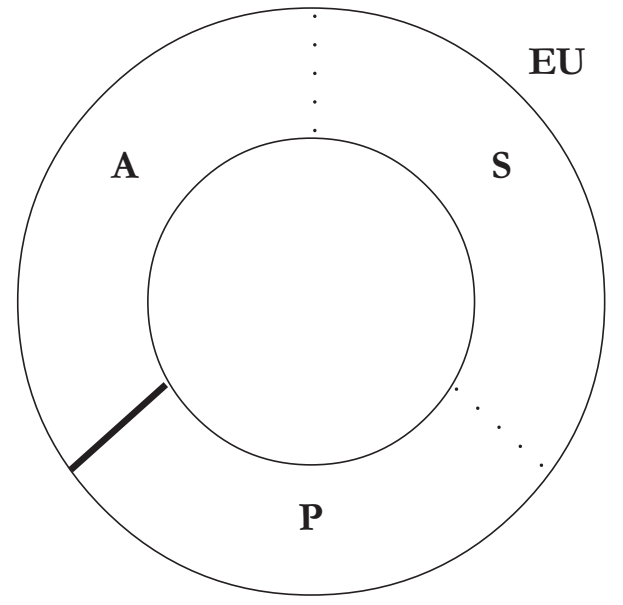

Figura 6 - Entre pensar e agir a troca livre está bloqueada

No caso da Figura 7, a troca livre está bloqueada entre agir e sentir. $\mathrm{O}$ agir é dirigido para o pensar, sem consciência dos sentimentos. Quando se permite sentir, isso se dá somente mais tarde. E sua linguagem não verbal acontece sem ou com pouca expressão. Para as outras pessoas, ele parece um robô, interesseiro, sem sentimentos, incompreensível porque sua linguagem não verbal não participa. Essa pessoa mantém uma distância e não compreende porque as outras querem ser tão sensíveis. Pode produzir muitas análises de sentimentos e emoções sobre as outras. No caso de expressar eventualmente seus sentimentos e emoções, precisa de muitas palavras, desculpando-se.

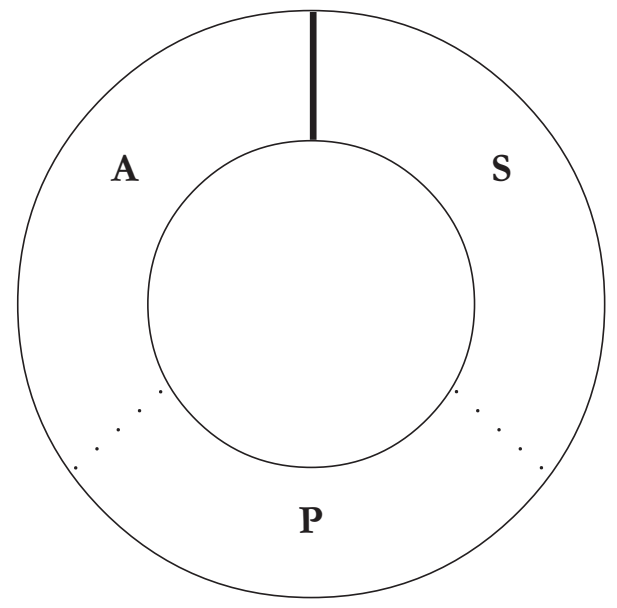

Figura 7 - Bloqueio entre ser e agir
Embora sejam semelhantes, o exemplo apresentado na Figura 8 não é igual ao da Figura 4. Esta pessoa é presa em sentir.

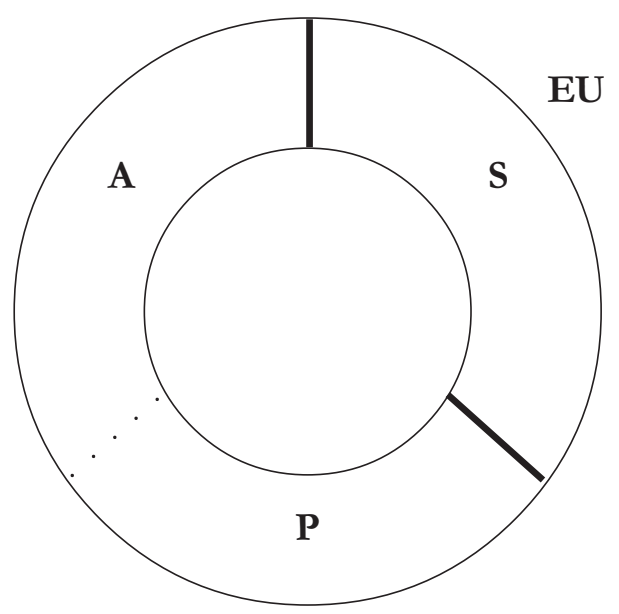

Figura 8 - O indivíduo encontra-se preso no sentir

Na Figura 9, a pessoa está presa no agir, isolada do sentir/pensar.

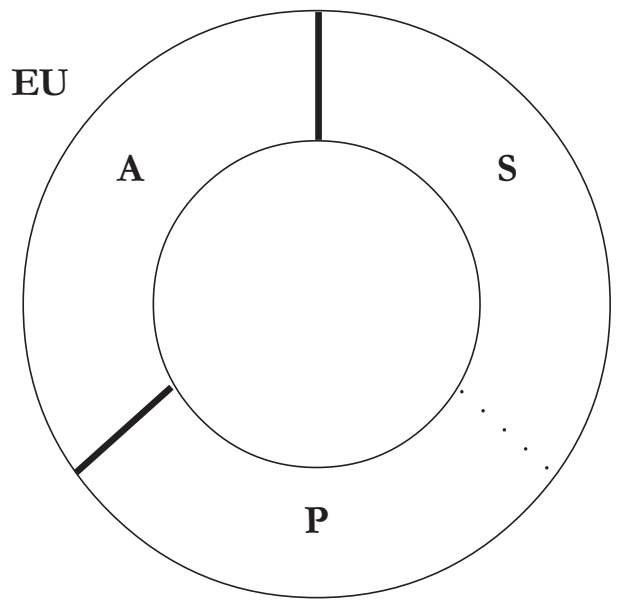

Figura 9 - Indivíduo preso no agir

Finalmente, a Figura 10 representa uma pessoa presa no pensar. 


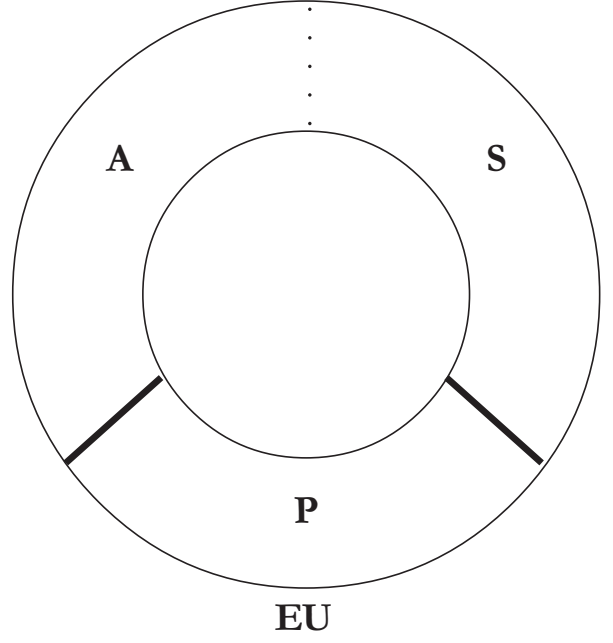

Figura 10 - Indivíduo preso no pensar

Isso não quer dizer que uma pessoa pode ser caracterizada por um só desses salva-vidas. Às vezes os bloqueios são apenas temporários, às vezes dependem do ambiente. Numa partida de xadrez, Pedro, professor de fotografia, pode ser como na Figura 4; nas aulas, como na Figura 5; procurando um alvo para fotografar, Figura 3; discutindo com a sua mulher, Figura 7. Os bloqueios podem variar dependendo dos impulsos do mundo externo. Sandra pode apresentar geralmente o modelo de comportamento descrito na Figura 3, mas basta ver um gato desnutrido ou um passarinho ferido para mudar repentina e involuntariamente para o da Figura 8.

Em todos os salva-vidas mencionados existem sinais específicos, indicando qual compartimento do salva-vidas pode ser dominante, temporário ou permanente. Existem sinais na língua, no comportamento e no corpo. Seguem alguns exemplos:

a) Pensar: utilização dos verbos 'pensar', 'achar', 'saber', 'presumir'/ ponderar ou ficar mudo / olhar para cima, franzir.

b) Sentir: utilização dos verbos 'sentir', 'gostar' ou cheirar, rir, suspirar, bocejar / corar, brilhar, vibrar.

c) Agir: utilização dos verbos 'fazer', 'ir', 'prosseguir', 'agir' ou não poder parar, desenhar, contribuir, tamborilar / sentarse aprumado, olhar atento em redor.

Merecem aplausos os dirigentes que reconhecem, respeitam e utilizam as características individuais de cada membro, permitindo a consciência do salva-vidas de cada um e incentivando o reconhecimento e utilização das diferenças entre os membros. E o mesmo para o professor com os seus alunos. Reuniões e aulas de qualquer tipo podem ser muito mais agradáveis e úteis quando todos os participantes souberem pilotar o seu próprio salvavidas. Além disso, é muito interessante observar um diálogo, numa reunião ou aula, entre os diversos tipos representados nas figuras anteriores. Nos palcos e cinemas de todo mundo, a brincadeira do salvavidas tem atraído milhões de espectadores.

\section{Filtro 4 - As modalidades}

É o filtro que exprime as preferências sensoriais. Uma pessoa é mais visual, outra prefere o filtro auditivo, uma terceira usa mais o filtro do paladar, do olfato, ou ainda o tato ou o afetivo. Notase a utilização desses filtros nas reações de pessoas que se deparam com um novo projeto: "nunca vi uma ideia tão genial", "isto cheira à corrupção", "nunca ouvi sobre tal atrevimento", "colocaram o dedo na ferida", "que delícia que a consulta ao público foi satisfatória", "isto não vai funcionar".

O indivíduo visual vê mais do que sente ou do que ouve. As lembranças visuais (fotos ou filmes) são mais fortes e numerosas do que os provérbios, afirmações ou melodias. Buscando no passado pode dizer: "não tenho uma imagem desta situação". Estimulando outras pessoas talvez diga: "olhe, você tem que trabalhar com muito mais motivação". Ele só vai se envolver em um projeto novo quando observar "vejo as perspectivas de futuro", ou só reagirá quando perceber: “já não vejo remédio". Seus recursos mnemônicos são símbolos, fotos, palavras-chave.

$\mathrm{O}$ indivíduo auditivo reage totalmente diferente. Usa muitos provérbios, lembra-se de conversas textualmente, dá conta do que foi dito em uma reunião anteriormente. Buscando no passado, pode repetir (em voz alta ou dentro de si) a palavra de busca. Estimulando outras pessoas, diz: “escute, as coisas não se dão assim...”. Preocupase, em um projeto novo, com "o que as outras pessoas vão dizer...". Seus recursos mnemônicos são provérbios, rimas ou melodias.

O indivíduo cinestésico lembra-se muito mais facilmente das ações, dos acontecimentos e vai se dar conta, em uma reunião, das sensações e das impressões emocionais. Buscando no passado, pode 
repetir um movimento. Ao estimular outras pessoas, pode dizer: "isto não vai colar...". Seus recursos mnemônicos são ritmos, movimentos e posições.

$\mathrm{Na}$ escola pode-se observar: João aprende as sequências de palavras em inglês dentro dos poemas, mas sua gramática é falha. Amanda tamborila irritantemente quando está aprendendo palavras em inglês. Pedro necessita de tudo por escrito e esquece os assuntos verbais instantaneamente, além de estar sempre perguntando o que tem que fazer. Carolina odeia os testes de compreensão oral, mas adora os vídeos de entrevistas.

As modalidades, além disso, são subdivididas. Alguns exemplos das submodalidades (Tabela 3):

Tabela 3 - Exemplos das modalidades

\begin{tabular}{|c|c|}
\hline VISUAL & AUDITIVO \\
\hline $\begin{array}{l}\text { Foto/filme } \\
\text { Enquadrado/fora do quadro } \\
\text { Panorâmico/fechado } \\
\text { Colorido/preto-branco } \\
\text { Pastel/cores primárias } \\
\text { Tamanho do quadro } \\
\text { Distância } \\
\text { Bidimensional/tridimensional } \\
\text { Intensidade de luz } \\
\text { Contraste/sem contraste } \\
\text { Movimento rápido/lento } \\
\text { Foco: nítido/vago (parcial ou totalmente) } \\
\text { Posição do observador: em cima/embaixo/do lado } \\
\text { Contexto/só imagens } \\
\text { Dimensão do tema central em comparação com o quadro inteiro } \\
\text { Só uma vez/repetitivo }\end{array}$ & $\begin{array}{l}\text { Volume } \\
\text { Ritmo } \\
\text { Tempo } \\
\text { Timbre } \\
\text { Altivez } \\
\text { Som forte/fraco } \\
\text { Mono/estéreo } \\
\text { Distância } \\
\text { Clareza } \\
\text { Contraste } \\
\text { Digital/analógico } \\
\text { Número de fontes do som } \\
\text { Fonte interna/ externa } \\
\text { Registro (como/quantas vezes/quanto tempo) } \\
\text { Só uma vez/repetitivo }\end{array}$ \\
\hline $\begin{array}{l}\text { CINESTÉSICO PRIMÁRIO } \\
\text { (tátil: sensibilidade da pele/movimento na cavidade torácica ou } \\
\text { intestinal e os membros) } \\
\text { Temperatura } \\
\text { Textura } \\
\text { Tremor } \\
\text { Pressão } \\
\text { Movimento } \\
\text { Velocidade } \\
\text { Tempo } \\
\text { Continuidade } \\
\text { Intensidade } \\
\text { Lugar } \\
\text { Ordem } \\
\text { Frequência } \\
\text { Estimulante (excitando/inexpressivo) }\end{array}$ & $\begin{array}{l}\text { CINESTÉSICO META } \\
\text { (sentimentos sobre outras observações) } \\
\text { Furioso } \\
\text { Irritado } \\
\text { Excitado } \\
\text { Triste } \\
\text { Medroso } \\
\text { Calmo } \\
\text { Alegre } \\
\text { Amando } \\
\text { Magoado } \\
\text { Desiludido } \\
\text { Abandonado } \\
\text { Atrapalhado } \\
\text { Confuso }\end{array}$ \\
\hline $\begin{array}{l}\text { CHEIRO / GOSTO } \\
\text { Gostoso/repugnante } \\
\text { Estimulante/insípido } \\
\text { Temperado/insosso } \\
\text { Picante/azedo/doce/amargo } \\
\text { Excitante/paralisante } \\
\text { Maduro/verde } \\
\text { Suculento/seco } \\
\text { Duro/mole }\end{array}$ & \\
\hline
\end{tabular}




\section{Filtro 5 - Aspirar ou evitar}

Carlos é um medroso, esgotando-se, se for preciso, para evitar alguma falta ou fracasso, e passar despercebido. Irene quer se corresponder com uma amiga inglesa, mas a gramática deixa-a infeliz. Paulo quer sair da universidade, quer trabalhar, só precisa da formatura! Luiz deseja ser veterinário e trabalha muito.

Evitar Aspirar (afastar-se do 'problema')

(buscar atingir seu 'sonho')

Dar feedback pode ser uma forma de evitar erros no futuro ou de visualizar os progressos.

\section{Filtro 6 - Procurar as diferenças ou as semelhanças}

Dorli: - Que legal que você sempre repete as aulas antes do testes. O Sr. Pereira faz. o mesmo.

Celso: - Mas ele corrige mais rápido!

A Tabela 4 traz os aspectos de dois posicionamentos distintos diante das questões cotidianas: a procura por diferenças e semelhanças.

Tabela 4 - Diferenças e semelhanças

\begin{tabular}{|c|c|}
\hline Procurando diferenças & Procurando semelhanças \\
\hline Nota inicialmente o que falta? & Nota inicialmente o que está presente? \\
\hline $\begin{array}{l}\text { A sua base é a desconfiança ou falta de confiança em } \\
\text { si mesmo? }\end{array}$ & Parte da confiança ou boas intenções? \\
\hline Nota alterações por perceber que algo sumiu? & Nota al terações por observar o que é novo? \\
\hline A sua primeira reação é um contra-argumento? & A sua primeira reação é um argumento de apoio? \\
\hline Reage frequentemente contestando? & Reage frequentemente concordando? \\
\hline $\begin{array}{l}\text { Relaciona em primeiro lugar as falhas da outra } \\
\text { pessoa? }\end{array}$ & $\begin{array}{l}\text { Relaciona em primeiro lugar o que reconhece, } \\
\text { aprecia ou entende da outra pessoa? }\end{array}$ \\
\hline
\end{tabular}

\section{Filtro 7 - Comparar}

Quais são os critérios para avaliar a si mesmo e as outras pessoas? As possibilidades são as seguintes:

a) si mesmo com si mesmo (S) / si mesmo com uma outra pessoa $(\mathrm{O})$;

b) usando a sua própria realidade (r) / usando a realidade da outra pessoa (r); c) usando o seu EU-ideal (i) / usando a sua imaginação idealizada sobre a outra pessoa (i).

Dessa forma, as combinações podem ser:

a) Sr / Sr: o que fiz melhor que ontem ou em qualquer outro lugar;

b) Sr / Si: o que não fiz tão bem quanto queria; 
c) Sr / Or: o que fiz melhor/pior que a outra pessoa;

d) Sr / Oi: o que vou fazer pior que a outra pessoa (sem provas disso);

e) $\mathrm{Si} /$ Or: o que quero fazer melhor que a outra pessoa fez hoje;

f) Si / Oi: o que tenho que fazer melhor que a outra pessoa sem saber se ela realmente sabe fazer isso tão bem.

\section{Filtro 8 - O ponto da referência}

O ponto pode ser interno ("posso escrever uma redação deste livro", "não gosto de ir ao cinema em grupos") ou externo ("senhora, fiz bem assim?"). Com o ponto externo da referência (PE), a pessoa se avalia utilizando o que as outras pessoas acham de bom ou ruim nela ou que dela esperam (os pais, colegas, professores, pares). No ponto interno da referência (PI) só existe uma pergunta: "o que é que $e u$ acho bom ou ruim". São necessários valores fortes para adotar essa posição. Pode ser que os valores sejam os mesmos dos pais. Mas você concorda e decide deliberadamente adotá-los. Nem o quadro interno nem o quadro externo são bons ou ruins. Ambos têm vantagens/ possibilidades e prejuízos/restrições.

Com restrições do PE, pode ser que a pessoa não tome iniciativas, mas seja um bom colaborador. Com restrições do PI pode ser que a pessoa precise trabalhar sempre sozinha, andando à frente do grupo, mas ela tem iniciativas e busca aventuras.

Combinando esse filtro com o do salvavidas, obtemos muitas combinações interessantes e complexas. Os compartimentos sentir e pensar de um colega estão dirigidos pelo ponto externo, mas seu agir está dirigido pelo ponto interno. Num outro colega, o sentir está dirigido pelo ponto interno e o agir e pensar estão dirigidos pelo ponto externo. Isso pode estar relacionado com as dificuldades de gerenciamento das chefias.

\section{Filtro 9 - A observação de si mesmo: No palco ou na sala}

Quando uma pessoa assiste à sua vida do palco, existe sempre o contato com os outros atores e o público, conscientes das próprias observações e memória. É uma experiência muito diferente de ser um espectador da sua vida, ouvindo e vendo a si mesmo no palco a uma certa distância. Há situações em que é muito proveitoso ser capaz trocar o jeito de se observar. Que difícil pode ser comunicar-se com um colega que não é capaz de, de vez em quando, observar a si mesmo.

\section{Filtro 10 - A perspectiva do tempo a respeito do presente, do passado e do futuro}

Como é o seu quadro do tempo:

a) Tem sonhos que quer realizar no futuro?

b) Tem experiências do passado que quer repetir?

c) Tem apenas um presente e não quer ser lembrado pelo que você disse ou fez no passado ou do que tem de fazer amanhã?

d) O presente está tão ruim, comparado com o passado, que não pode ver o futuro?

e) Está disposto a fazer sacrifícios hoje para obter um futuro melhor?

f) Pode ter um novo começo com a turma que foi tão desinteressada no ano passado?

g) Gostaria de refazer o passado para obter um presente ou um futuro melhor?

h) Não se preocupa com o futuro o tempo todo, podendo divertir-se no presente?

i) O seu futuro está restrito pelas escolhas ou experiências no passado?

j) Está acomodado pelas conquistas do passado, mas não sabe pôr-se em movimento atualmente?

k) Quão difícilé ter motivação para estudar muito quando não se sabe se haverá trabalho depois?

Acrescentando: no "teclado" de nossos filtros, a combinação com o filtro 7 (Comparar) é interessante:

- Ler inglês hoje é mais fácil que no ano passado $(\mathrm{Sr} \mathrm{Pr}-\mathrm{SrPa})$. $(\mathrm{SrPr}-\mathrm{SrF})$.

- Envelhecer é só perder as capacidades 
- Todos os colegas têm problemas com esta turma ( $\mathrm{SrPr}-\mathrm{OrPr})$.

- Meu irmão foi muito mais popular nesta empresa $(\mathrm{SrPr}-\mathrm{OiPa})$

\section{Filtro 11 - A experiência do tempo}

Há cinco aspectos:

a) A noção do tempo: sempre se perde na atividade do presente, esquecendo-se da hora.

b) O tempo do tempo: o tempo passa sempre rápido demais ou lento demais, diferente do que você quer.

c) Sendo ciente do tempo: consciente de cada minuto que passa e da quantidade de trabalho que tem que fazer ainda; tempo é dinheiro.

d) Limiar da frequência: ser tão avesso a um procedimento de uma outra pessoa, que não permite que ele se repita.

e) Limiar de tolerância: quantas vezes precisa se irritar com um comportamento antes de intervir?

Os três primeiros aspectos influenciam, por exemplo, como os estudantes experienciam as aulas/assistem a elas, ao ambiente e ao tempo. Os dois últimos influenciam as respostas adequadas e pertinentes às ocorrências no ambiente. Alguns colegas não devem receber ordens demais. Muitas vezes, eles têm um limiar de frequência baixa. Outros precisam ser ordenados mais vezes. E quem erra uma vez sabe que pode ser demitido com o próximo erro. Alguns colegas podem ficar ofendidos muitas vezes com o chefe, mas não dizer nada.

\section{Filtro 12 - Os valores e convicções}

Um valor é alguma coisa que representa tanto para uma pessoa que essa se esmera para mantê-lo:

a) ser (presença, franqueza, receptividade);

b) ser autêntico (genuíno, honesto); c) ser livre (independência, liberdade);

d) ser colaborador (envolvimento, orientado para colaborar);

e) ser lindo (qualidade, estético);

f) ser muito (quantidade, eficiência, efetividade);

g) ser inovador (criatividade, movimento, desenvolvimento);

h) ser amável (harmonia, empatia, serviçalismo);

i) ser honesto (justiça, honestidade, credibilidade).

Uma convicção é uma verdade pessoal, que se defende e se observa. Juntos, os valores e as convicções são um filtro forte para selecionar impulsos do mundo e para representar-se. Através deles, você se distingue/separa-se do ambiente ou dissolve-se no ambiente.

Ocorrem problemas quando dois valores são contraditórios, ou seja, quando se diz ou age de alguma maneira, mas não se está convencido. Por exemplo: um jovem precisa de seu trabalho aos sábados para financiar sua moto e ser popular, mas também quer aproveitar a vida e ir com os seus amigos para a universidade.

Ocorrem problemas quando algumas convicções não são escoradas em valores. Um jovem modesto tenta ser popular com os seus companheiros, contestando o professor. Quando o conflito vai aumentando, ele se afasta sempre mais do seu próprio núcleo, a modéstia. Ocorrem problemas por causa das convicções restritivas: "os pais não vão achar engraçado se mudo para outro Estado, mas preciso de emprego" ou "não estou com bastante inteligência para aprender espanhol".

\section{Filtro 13 - O nível da fragmentação e abstração}

Lendo a palavra 'pão', há pessoas que recordam imediatamente de um pão de 800 gramas (os generalistas); outras recordam uma trincha ou um bocado de pão (os detalhistas).

Os generalistas falam das unidades grandes, de uma abstração mais alta, precisam de traços largos e perdem-se ou ficam confusos quando os colegas falam de detalhes. Os detalhistas são acostumados a pensar em detalhes e precisam ser servidos com 
informações passo a passo. Eles se inclinam a tirar conclusões com base em poucos dados e entregamse a abstrações.

Nenhum desses comportamentos é bom ou mal. São apenas dois jeitos de tratar os estímulos do mundo. Só ocorrem problemas quando cada um crê que o outro jeito é insensatez ou perda de tempo.

\section{Filtro 14 - O tipo da recordação primeira}

A seguinte situação hipotética ilustra a utilização do filtro 14. Um funcionário de uma empresa não pôde comparecer a uma reunião importante e, no outro dia, perguntou a cinco colegas se poderiam descrever como havia sido o encontro. Cada um deles representa aqui um dos tipos da recordação:

a) Tipo 1: vai recordar os outros ausentes. Quando ele conta das férias, fala sobre os encontros.

b) Tipo 2: preocupa-se normalmente com objetos, o arranjo dos objetos ou objetos novos. Pode recordar da reunião o traje do presidente. Das férias conta dos presentes que comprou.

c) Tipo 3: vai recordar do que se passou, os acontecimentos e a ordem desses. Das férias, fala a respeito de atividades e excursões.

d) Tipo 4: preocupa-se com o lugar. Da reunião conta do calor, das cores horríveis da sala e das cadeiras incômodas. Das férias, conta da cidade, das lojas e igrejas.

e) Tipo 5: vai recordar todas as informações novas que ouviu na reunião ou nas férias. Trata-se do tipo da recordação primeira (pessoas, objetos, ações, lugares, informações).

\section{Filtro 15 - O tipo da reação quando decisões precisam ser tomadas}

Há pessoas que querem gerar e manter abertas tantas opções quanto possível. Outras querem voltar imediatamente às regras, procedimentos e convenções do passado. E há ainda outras, as quais pedem que todos se apeguem às estruturas.

Essa enumeração dos filtros não basta para aperfeiçoar a sua comunicação. Em cada filtro, o texto dá alguns exemplos dos sinais desse filtro, seja do comportamento, da língua maternal, ou língua pessoal. Precisa-se perceber e empreender muito mais os sinais, em seu próprio comportamento, sua língua, seus sentimentos, suas emoções e suas convicções. Depois, pode-se perceber e responder aos sinais das outras pessoas.

\section{AGRADECIMENTOS}

Agradeço a Renate Vicente e Luiz Vicente, pela ajuda na tradução do artigo.

\section{REFERÊNCIAS}

Bandler, R., \& Grinder, J. (1975a). The structure of magic I: A book about language and therapy. Palo Alto, CA: Science \& Behaviour Books.

Bandler, R., \& Grinder, J. (1975b). The structure of magic II: A book about communication and change. Palo Alto, CA: Science \& Behaviour Books.

Recebido:19/11/2008 Received: 11/19/2008

Aprovado: 24/03/2009

Approved: 03/24/2009 